some solution, such as permanganate-the only disinfectant we had in any quantity in the earlier days; later, when we had supplies, hydrogen peroxide was substituted, and, as a result, parotitis, otitis, and other naso-pharyngeal disturbances disappeared. Constantly swabbing the back of the throat considerably ameliorated the condition of deafness. Patients who were able were taught to gargle periodically throughout the day, and as a result the laryngeal trouble was improved.

\section{Circulatory Disturbances.}

Another condition which caused us much anxiety, and which occurred frequently in asthenic cases, was the circulatory tiouble. For a considerable time we were unable to account for this. All. that we noticed to begin with was that the feet and hands became blue and cold, and the pulse small and thready, indicating a general cardiac failure. But, apart from this, we found that we had to deal with local degenerative troubles. Patches of redness usually appeared on the feet, active congestion evidently occurring there, and later this was followed by patches of gangrene. Sometimes the toes would be symmetrically affected, would disorganize and fall off. We had two cases in which the nose was affected. The fingers, though frequently showing the earlier signs, never, in cases under my observation, went on to gangrene, but, in fact, completely recovered.

The general plan adopted in these cases was that, when the feet showed coldness and blueness, hot-water bottles were at once applied, and a supporting treatment was also adopted. Strychnine and digitalis were frequently injected, brandy occasionally administered, and, when possible, massage was given. If the condition of the extremities did not improve under this treatment but pro. ceeded to redness, then evaporating lotions were applied, and these measures met with a fair amount of success.

If one were to form a surmise one might venture to say that the extremities were the parts most likely to become morbid, in view of the fact that they were the parts exposed to the detrimental action of frost and cold in the trenches, and that in all cases it might be said there was a previous degenerative disturbance due to long exposure to cold. It is well known, for instance, that a frost-bite, once obtained, leads to a tendency to recurrence under conditions which would not otherwise produce a frost.bite, and so in this condition we have such a grave circulatory disturbauce that with the acute toxaemia of the disease and the preceding history of frost-bite there was a suffi. cient local disturbance to bring about a further depression of the circulation and a condition of gangrene.

Temperature.

On the second or third day of the onset of malaise the temperature gradually rises, until it reaches $103^{\circ}$ on the fourth or fifth day. This temperature is continuous, occasionally rising to $104^{\circ}$, until it ends in lysis. In some cases the temperature is remittent, and these, together with the fulminating cases, are the types which give the most anxiety. The cases with remittent temperatures caused the greatest anxiety after the subsidence; they were probably due to the associated cardiac disturbancethe failure of the cardiac muscle to respond to the toxins. The fulminating cases usually displayed. continuous tenperatures.

\section{Pulse: Respiration.}

The pulse was never very rapid and was usually associated with the temperature. The respiration was, however, frequently entirely disassociated with the tempera. ture and pulse, and in some cases, until we gained larger experience, this disassociation with the temperature and pulse caused us grave anxiety. We felt it represented a definite local toxaemia of the medulla and to be the prelude to dissolution. Fortunately, however, with a wider experience we found that this disassociation was not a grave matter. A pulse of 98 and a temperature of $101^{\circ}$ was occasionally combined with a respiration of 45 . There never was the least sign of pulmonary stasis, and this is one of the most remarkable features of the typhus epidemic, considering the amazing depression of all the tissues together with the cardiac asthenia, that congestion and oedema of the lungs was not more frequently met with. In very few cases indeed did we know of any lung trouble at all, and these were only due, it was said, to secondary invasion. Iu only one case under my observation did we get a bronchopneumonia, which is usually considered a frequent sequel, a result of the extension of the infection of the organism from the mouth down the larynx into tlie bronchi.

Treatuent.

Finally with regard to treatment. A supporting dict, which usually included soups. Benger's food, Horlick's milk, and so on, was administered for the first fortuight. Occasionally brandy was given, but not often. There is a great prejudice in the Balkans against the use of brandy for typhus. One must acknowledge the right of the local opinion in this matter because of the considerable experi. ence they have of the local form of typhus; they declare, and we think with good reason, that alcohol in any form aggravates the cerebral symptoms, which are such grave and important indications of brain toxaemia.

It must be remarked, therefore, that the next point in treatment which they always insist upon, and which is a corollary of the above, is the application of ice to the head. Ice was placed on the head fron the onset, and maintained there until the subsidence of ferer, and, if one can generalize at all, one may say with the greatest benefit. As has been stated, the mouth was attended to every halfhour throughout the day. In some cases sordes collected almost as quickly as it was wiped away. The patient was always moved very carefully, and turned from side to side to avoid bedsores, which occurred with amazing firequency considering the short duration of the decubitus. The extremities were kept warm. There was of course the greatest insistence on fresh air, and the window frames in the wards were removed. This appeared to the majority of patients to be, of all things, their greatest hardship when the icy winds of March were blowing. through. In fact, patients of all classes in the Ballkans always corcr their heads when going off to slcep, and it was the duty of the nurse to see that their heads wore uncovered, and that breathing was free and comfortable. At one time wo thought that if we were to insist sufficiently on the principles of fresh air we should do much to diminish the virulence of the toxaemia, but we are unable to say that it had that profound effect we anticipated. The tradition of typhus is that it is associated with filth, overcrowding and the absence of fresh air, and of course it was beliered that if one could provide cleanliness, space, and fresh air. one would do much to diminish the virulence of the fever. But our experiences went to show that here fresh air was not apparently the potent factor that it is advertised to be, though naturally fresh air in all disease is a sine qui non.

\section{ARTIFICIAL PNEUMOTHORAX IN THE TREAT- MEN'T OF PULMONARY TUBERCULOSIS.}

\section{a Clinical Study of Eighteen Cases.}

C. H. VROOMAN, M.D., C.M.

MEDICAL SUPERINTENDENT, KING EDWARD SANATORIUM, TRANQUILLE, KAMLOOPS, B.C.

THE object of this paper is to give a brief account of our clinical experience at Tranquille in the treatment of pulmonary tuberculosis by compression of the lung with artificial pneumothorax in a series of 18 cases. The literature on this subject during the past two years has been very extensive, and the selection of cases, results obtained, and obstacles to be overcome in the use of artificial pneumothorax are still too much in the formative stage for any one to be too dogmatic. It is through correlating the experience of many independent observer's in different circumstances that we can hope to ascertain the true place of this procedure.

Artificial pneumothorax was first used by us at Tranquille in December, 1913, and since that date we have tried to give 18 patients this treatment. The apparatus used was a modification of the Floyd-Robinson. ${ }^{1}$ We were forced to make our own apparatus as a matter of economy, and havo found it to work quite satisfactorily. At first we used nitrogen gas obtained by abstracting the oxygen from tho air by pyrogallic acid and potash solution. After reacling the research work of Webb and others ${ }^{2}$ we came to the conclusion that sterile air would be quite as good and less troublesome, and for some months past we have been using 
sterile air. Our results have been quite as good and we have not found that we had to make refills any oftener. We unfortunately have no $x$-ray apparatus at the sanatorium, so that we were not able to check our findings by this means.

The technique has been that most commonly usednamely :

1. Sterilization of the skin with tincture of iodine.

2. Injecting 4 per cent. novocain as a local anaesthetic. The important point here is to inject the novocain deeply, so that the parietal layer of pleura is anaesthetized as well as subcutaneous tissues.

3. Puncturing the skin with a sharp, thin-bladed knife.

4. Inserting the blunt Floyd needle. With practice we have found that one could tell when the needle had passed through the parietal pleura by the slight popping sound heard, like sticking a needle through a tense piece of cloth. The site of injection has been by preference the fourth or fifth interspace in anterior or mid-axillary line, though sometimes it has been found necessary to go much further back.

5. After withdrawing the stylet of the needle to get a proper fluctuation in the manometer. This is the crux of the whole proceeding. Once a proper fluctuation is obtained the rest is easy. In favourable cases, at the first injection slight withdrawal of the needle, and with very little manipulation, a good fluctuation was obtained almost at once. It has averaged from negative $2 \mathrm{~cm}$. to negative $4 \mathrm{~cm}$. (water). Unfarourable cases-that is, cases in which there were many adhesions-often required prolonged manipulation, and then only a very slight fluctuation of 0 to $0.5 \mathrm{~cm}$. was obtained. Several times we punctured the lungs during our manipulations. Beyond the spitting of a little blood-streaked sputum it did no liarm. After getting a fluctuation the gas or air may be allowed to flow in at the rate of about $100 \mathrm{c.cm}$. a minute, manometric pressure being taken after every $100 \mathrm{c.cm}$.

\section{Refills.}

The average amount injected at the first operation was $734 \mathrm{c.cm}$. The highest quantity was $1,200 \mathrm{c.cm}$. and the lowest $195 \mathrm{c.cm}$. In the earlier cases as much as 1,000 c.cm. to 1,200 c.cm. were injected at the first sitting, and though the patient showed no subjective symptoms at the time, yet we found symptoms sometimes developed within an hour or troo, and now I consider $500 \mathrm{c.cm}$. to 600 c.cm. quite sufficient for the first injection. At subse. quent refills the sensations of the patient have been our best guide. Severe pain, shortness of breath, and sensation of tightness or coughing, are all signs showing that enough had been injected. Even in the absence of sensations we have found that when pressure in the manometer went to about $4 \mathrm{~cm}$. or $6 \mathrm{~cm}$. positive water pressure it was time to stop, as we were liable to have subcutanenus emphysema if more were injected. This, while not a dangerous complication, is unpleasant. During the injection a number of our patients complained of pain in the shoulder. This was due to stretching of diaphragmatic adhesions, and is an excellent example of referred pain as pointed out by James Mackenzie. ${ }^{3}$. In attempting to give this treatment to cases in which there were many adhesions and considerable fibrosis we have met with great difficulty. In some cases in which we had been able to get $500 \mathrm{c.cm}$. to $700 \mathrm{c.cm}$. of gas in the first time and which showed on examination a partial pneumothorax, we were greatly disappointed in that we had as much, if not more, difficulty with the refills.

In a number of those classified below as Group 2 we have secured a fair fluctuation, from zero to $0.5 \mathrm{~cm}$. or even $1 \mathrm{~cm}$., and proceeded to allow the gas to flow in. On testing it from time to time we found no change in the fluctuation, and even as when in one case we allowed $3,000 \mathrm{c.cm}$. to flow in, the patient noticed no increasing tightness or any symptoms whatever. The only explanation, of course, is that the gas escaped into the parenchyma of the lung, either through puncturing a cavity or small bronchus. I have never seen any harm result from this, in fact the patients often assert that they felt better because of the large amount of gas they were able to take.

We have given in all 202 injections, and in one case we had symptoms of pleural reflex. The patient stopped breathing and went into a state of collapse, lasting one or two minutes; another patient vomited after each injection, but the reason in both these cases was putting in too much gas at one sitting. From my experience I would say that it is racely advisable to give more than $700 \mathrm{c.cm}$. to $1,000 \mathrm{c.cm}$. of gas at one sitting, unless it is necessary to get a rapid collapse to stop haemoptysis. Pleuritic effusion has been diagnosed in three of our cases. It has possibly been present in more, as in one case it was discovered by $x$-ray examination while the patient was away at the neighbouring town, and had been entirely overlooked in our physical examination. The quantity was small, and possibly if all our cases had been systematically screened we would have found more effusions. It developed in each case after the patient had been treated for some time.

\section{Cases Treated.}

The cases we have attempted to treat by pneumothorax may be divided into three groups.

Group 1 (3 Cases). - Far advanced febrile cases with bad prognosis, the disease being mostly confined to one side, but some involvement of the other lung. We treated three of this type. In all of them the prognosis was absolutely bad. One had only one injection, and refused to go on. He died two months afterwards. Of the othcr two, in one a partial, and the other a good pneumothorax was obtained. One died in two months, the other in eighit months. Both claimed that their symptoms were better after treatment, but I do not think the treatment hastened or delayed the inevitable result.

Group 2. (8 Cases).-These were far-advanced longstanding chronic cases, mostly non-febrile. In this group the cases were those in which there was extensive involve. ment of most of one lung with long-standing cavity. The other was involved, but had undergone considerable tibrosis. They had all been under sanatorium treatment for a long time, some of them for years. Their condition had in each case been stationary for a long time under ordinary sanatorium life. The pneumothorax treatment was given with the hope that the outlook of a life of chronic invalidism might be changed into one of at least partial usefulness. That this hope was not realized in these cases is one of our great disappointments in this treatment. The average time from onset of the disease to the time of doing pneumothorax on these cases was forty-two months. T'hey were all difficult to treat on account of adhesions and the general fibroid condition of the lung. In 3 a good pneumothorax was obtained, in 5 a partial one, and in 1 we could not find the pleural space. In 3 there was partial benefit, symptoms of cough and sputum being lessened, but no marked improvement in their general condition. Of the 5 in whom a partial pneumothorax was obtained after six months' treatment, in none could signs of a pneumothorax be found. Their condition was practically the same as when the treatment had been started. The air had escaped into the parenchyma of the lung either through rupture of adhesions or punctures made at refills. I could not see that the treatment had done them any harm, and they were all rather disappointed when the treatment was discontinued. These old-standing cases are not likely, unfortunately, to be benefited by this treatment. Adhesions and general fibrosis hinder collapse of the part of the lung we want collapsed, and should one obtain a partial pneumothorax it is the remaining healthy lung tissue which is collapsed rather than the diseased area. However, I still think it is worth trying to get a collapse in those cases in which the disease is unilateral, as occasionally a case in which a good collapse is obtained will improve considerably, and a bad prognosis modified if not absolutely changed. If, though, after two or three refills, it is still difficult to find the pleural cavity and signs of collapse are not marked, it is hardly worth while persisting.

Group 3 (6 Cases).-This is the most encouraging group of the series. They were all, except one, far advanced cases, but the onset had been recent. The average time since onset of the disease to the time of doing a pneumothorax was 7.8 months. The disease was more active than in Group 2, as indicated by moist râles, rapid pulse, and slight rise of temperature. It was not so extensive, and, as far as I could tell, very little fibroid change. In all this group a good pneumothorax was easily obtained, and refills were made without any trouble whatever. Everv 
one of this group showed marked symptomatic improvement, and all but one improved in their general condition, as denoted by gain in weight and ability to take exercise without rise of temperature. One has been under treatment sixteen monihs, two eleven months, and they have shown such marked improvement that a bad prognosis has been changed to.a good one, and we can be liopeful in each case of a permanent arrest of the discase. 'The other's have only been under treatment from four to six months, but they are all showing marked improvement. 'Their improvement has been more rapid with pneumothorax than it was under exactly the same conditions without it.

Our experience in this group may be illustrated by one typical case

A. R. G., male, aged 25, physician, had always had good health until onset of present illness. Onset of illness, December 1st, 1913, with rather severe haemoptysis. Admitted to the sanatorium January 14th, 1914 . Weight, $120 \mathrm{lb}$. Average afternoon temperature, $99.4^{\circ} ;$ pulse, 90 . Examination of chest showed: light, consolidation of upper lobe, and infiltration of showed : light, consolidation of upper lobe, and the apex and upper part of mid-lobe; left, thickened pleura at the apex and some fibrosis, probably due to an old lesion. The patient did well fus cim of somer for a time under sanatorium treatment, but then had anotber haemoptysis in April, developed an afternoon temperature of $100^{\circ}$, and examination of chest showed extension of the disease. In June, after five months' sanatorium treatment, two-thirds of right lung involved, with signs of cavity in upper lobe. There were a few fine crepitations at left base. He also developed a fistula in ano, which was discharging quite freely. June 26th, 1915, artificial pneumothorax was done on the right sicle. There was no difficulty in finding the pleural cavity, and a fluctuation of negative $2 \mathrm{~cm}$. to negative $4 \mathrm{~cm}$. (water) was obtained at once; $850 \mathrm{~cm}$ of gas was injected the first time. Six days later he was given $1,100 \mathrm{~cm}$ twelve days later Six days later he was given $1,100 \mathrm{~cm}$. There was evidence 1,250 c.cm., alla in of a good collapse, and since then he has received refills of from $600 \mathrm{c.cm}$. showed marked improvement from the beginning: temperature stre occasions slightly streaked sputum. In January last his condition was so far improved that he was operated on for the cure of the fistula in ano. He took the anaesthetic well, and stood a rather extensive operation well. Since then his improvement has been rapid. At present date his general condition is good; temperature normal, pulse 90 ; weight, $130 \mathrm{lb}$. (normal weight for him). There is a good collapse of the right lung; $x$-ray examination showed a slight amount of fluid present. His throat condition has cleared up, and the fistula in ano was healed.

I have given a rather lengthy account of this patient as I consider this the type of case in which we are likely to to get good results from pneumothorax treatment. My logret in this case is that we did not compress the lung at the beginning.

\section{Conclusion.}

To draw conclusions from so limited a number of cases is somewhat dangerous, and it would be absolutely unfair to judge the merits of the treatment from the results obtained from these 18 cases. Of the first 12 of the series 9 were failures and only 3 showed partial benefit. This was because they were long-standing cases, in which there was an absolutely bad prognosis any way. To obtain good results we must, I am convinced, use this treatment in those of recent origin.

The moderately advanced case of recent onset, with the discase confined almost altogether to one side, is the type of case in which we should produce a pneumothorax at once. Many of these progress rapidly, and at the end of six inonthis must be classified as far advanced, so that by the usc of artificial pneumothorax we have a most valuable adjunct to our treatment. Incipient cases, with severe haemoptysis, should also be treated by pneumothorax at once. In so many of these there is such a rapid extension of the disease after haemoptysis that it is better to give them the benefit of this treatment. I cannot go as far as some and advocate that all incipient unilateral cases be treated, as our results with ordinary sanatorium treatment are good. My great complaint is, like that of all men in sanatorium work, that so few of these cases are sent for treatment. On the other hand, my experience does not encourage me to hope for much benefit from pneumo. thorax in the far-advanced, long-standing cases. I would distinguish here the far-adranced case which has recently bccome so, and that in which the disease has been of some ycar's' standing.
A case of recent onset, which from physical signs we must classify as far advanced, but which from general condition is still moderately advanced, is eminently suited for pneumothorax, provided, of course, the disease is mostly unilateral.

Artificial pneumothorax is, then, a valuable addition to our methods of treating tuberculosis, but unfortunately its application is restricted to not more than 5 per cent. of cases which have come under my observation.

1 C. H. Vrooman and F. REFERENCES.

F. Wittich: Journ. Amer. Med. Assoc. March 21st, 1914, vol. lxiii, p. 929. '2 Gerald B. Webl, G. Burtan Gilort, L. James, Leon C. Havens: Artificial Pneumothorax, with Report of Gas Analy'sis to determine the use of Air Nitrogen, Archives and their Interpretation, 1909, 1209.

\section{OUR PRESENT POSITION WITH REGARD TO THE PRESCRIPTION OF PROPRIETARY FOODS IN INFANT FEEDING."}

\author{
BY
}

HECTOR CHARLES CAMERON, M.D., F.R.C.P.,

ASSISTANT PHYSICIAN, AND PHYSICIAN IN CHARGE OF THE CHILDREN'S DEPARTMENT, GUY'S HOSPITAL.

In the artificial feeding of infants we must recognize two types of diet, and if we keep the distinction clearly in mind we shall be saved from a good deal of the confusion which at present hangs around the subject. In the first place we must recognize that for the normal healthy infant, who is unfortunate enough to be deprived of his mother's mill, there exists what we may call a standard substitute diet.

1. Cow's Milk as the Standard Substitute Diet.

It is the experience of all those who are best qualified to judge that in cow's milk we have tho most suitable standard diet available in a form that is cheap and easy to procure. It does not matter whether we use the cow's milk undiluted with the addition of a little sodium citrate, and we shall then obtain both the good effects and the bad effects of a diet of cow's milk in the purest and most pronounced form, or whether we dilute the milk by the admixture of water or barley water and add very small amounts of sugar. It does not even matter very much, broadly speaking, whether we use fresh milk or substitute for it a prepuration of condensed. milk-so long as we choose an unsweetened variety with all the cream retained-or one of the many preparations of dried milk which have now been placed upon the market. In every case the result which we shall attain will be very much the same.

The infant fed upon cow's milk in one form or another will show in his growth and development the marks of the character of his diet. If he does not rival the child at the breast in agility, in rapidity of growth and in resistance to infective catarrhs, at least there is much in his condition with which we may be well satisfied. A critical eye may note at times a laxity and flabbiness of the muscles; the skin may be a little pale, although this is often masked by a fixed colour in the cheeks due to a slight eczematous infiltration over the malar bones and at the point of the chin; the abdomen is sometimes too distended, and the um. bilical cicatrix may be unduly stretched; constipation is common and the putrefactive changes in the bowel are apt to be more prominent tiran the fermentative changes, and to make themselves evident by the characteristic smell of the evacuations; sweating is often excessive and micturition profuse; there may be some tendency to the appearance of transitory urticarial and erythematous skin eruptions. But these are small drawbacks to a diet which gives in general good results, and which can claim that it possesses one all-important advantage. Upon a diet of cow's milk the digestive processes of the infant are comparatively stable, and the infant runs little risk of such violent, daugerous, and even fatal attacks of diarrhoea and romiting as are common enough in children whose food contaius a high percentage of starches and sugars. I am not here speaking of the possibility that the contamination of the

* An address delivered at the Child Welfare and Mothercraft Exiuibition at the Passmore Ed wards Settlement, T'avistock Place. 